\title{
Students' assessment of paediatric teaching and their opinions 7 years later
}

\section{S. R. MEADOW}

From the Department of Paediatrics and Child Health, Leeds University

SUMMARY A prospective study of the long-term validity of student assessment of paediatric teaching began during the period 1968-70. The students gave scores to the different parts of the course in a standard questionnaire. Between 6 and 8 years later the same students were given the same questionnaire to complete. 76 of the original 92 students responded. By this time most of them were either principals in general practice, or senior registrars or consultants in hospital medicine. The 18 items in the paediatric course were given remarkably similar scores in the two questionnaires, and the popularity ratings of only 2 items had altered significantly during the 7 -year interval. The doctor 6-8 years after the course seems more likely to appreciate the need for teaching about communication skills.

The idea that students should evaluate their teaching meets a mixed response from medical teachers. Some teachers, strongly in favour, organise formal feedback sessions and questionnaires; others are equally strongly against. One common objection is that the student is immature and superficial in his judgement, so that the student's opinion of his teaching may be of little relevance to his final evaluation of it as a working doctor in the light of experience and knowledge.

A prospective study of the reliability of student assessment of paediatric teaching was begun in 1968, using a standard questionnaire in which different parts of the course were given scores by the students (Meadow, 1970). Between 6 and 8 years later the students were again asked to complete the same questionnaire. They were also asked to give information on their work since qualifying.

\section{Method}

Initial survey. During an 18-month period from 1968 to 1970 clinical students at Guy's Hospital, London, were given a questionnaire at the end of their 3month paediatric appointment. At that time they were in their penultimate clinical year. The questionnaire included a rating form (Appendix) in which 18 separate parts of the course were graded on a 4point scale to find out how useful each had been. The student could respond 'extremely valuable',

Received 10 January, 1978 'valuable', 'of little value' or, 'of no value' (and also 'not experienced' if he had missed that particular item). By taking the sum of the scores for each item, and dividing the result by the number of students experiencing that item, a percentage value figure was achieved which reflected its popularity or usefulness. Thus if every student who had visited Carshalton Hospital gave it the maximum rating, Carshalton would emerge with a percentage value figure of $100 \%$.

Final survey. In 1976, between 6 and 8 years after the first survey, we attempted to trace all the former students. In an explanatory letter they were asked to complete the rating form, and also answer some questions about the paediatric course selected from the full questionnaire which they had answered as students. They were asked to give details of their present appointment, any previous paediatric appointments, and their ambitions.

The results of the first survey were compared with the results of the second one, and then considered in relation to the doctors' careers and aspirations.

\section{Results}

Out of the original 92 students, 82 returned the second questionnaire. Those who could not be traced were mainly women who, presumably, had changed their names. Six of the forms were excluded because of lack of clarity, incompleteness or, in one instance, because the student had given up medicine. The 
information from 76 complete questionnaires is compared with the information given initially from the same 76 people when they were students.

Most of the doctors were either established principals in general practice or, if in hospital medicine, senior registrars. A few were consultants. The amount of time they were now spending working with children was 'substantial' for 30, 'moderate' for 23 , and 'minimal or none' for 23 . Exactly half had completed a paediatric house job during postgraduate training.

The career aims of the doctors were: paediatrics 7; general practice 27; hospital specialty-with children (for example surgery, radiology) 30; hospital speciality-no children (for example internal medicine, geriatrics) 12 .

The value ratings for each part of the paediatric course are shown in the Table, the initial rating being shown beside the final one. In 1969 the ratings ranged from $44 \%$ to an extremely popular item which was rated 92\%. By 1976 the range had narrowed slightly, from $45 \%$ to $82 \%$.

The Table shows the close similarity of the scores for 1969 and 1976. Nearly all items were within $10 \%$ of their previous score. The only item to appreciate in popularity with time was the acute take-in residence at Evelina Children's Hospital. The items to depreciate in the 7-year interval were $x$-ray tutorials (previously the most popular item of all), reading textbooks, and reading journals. The last item is likely to be misleading; several doctors in the 1976 questionnaire thought they had read no journals during the course, but admitted that they might have

Table Value rating of each component of the paediatric course (if each student rated an item 'extremely valuable' that item would score $100 \%$ )

\begin{tabular}{|c|c|c|c|}
\hline \multirow[b]{2}{*}{$\begin{array}{l}1976 \\
\text { rank }\end{array}$} & \multicolumn{2}{|c|}{ Value rating $(\%)$} & \multirow[b]{2}{*}{$\begin{array}{l}1969 \\
\text { rank }\end{array}$} \\
\hline & 1976 & 1969 & \\
\hline $\begin{array}{l}1 \text { Registrars' ward rounds } \\
2 \text { Take-in residence, Evelina Children's } \\
\text { Hospital } \\
3 \text { Carshalton Hospital residence } \\
4 \text { Tutorials } \\
5 \text { X-ray tutorials } \\
6 \text { Reading textbooks } \\
7 \text { Take-in residence, Guy's Hospital } \\
8 \text { Consultants' ward rounds } \\
9 \text { Developmental lectures, Newcomen } \\
\text { Centre } \\
10 \text { Outpatient clinics } \\
11 \text { Visit to juvenile court } \\
12 \text { Paediatric surgery teaching } \\
13 \text { Monday paediatric lectures } \\
14 \text { Burns teaching } \\
15 \text { Case conference, social paediatrics } \\
16 \text { Introductory course } \\
17 \text { Salomons Centre-infant welfare } \\
\text { clinic } \\
18 \text { Reading journals }\end{array}$ & $\begin{array}{l}82 \\
81 \\
80 \\
78 \\
72 \\
70 \\
67 \\
65 \\
\\
64 \\
58 \\
57 \\
57 \\
56 \\
55 \\
54 \\
54\end{array}$ & $\begin{array}{l}86 \\
\\
69 \\
83 \\
75 \\
92 \\
80 \\
66 \\
63 \\
\\
68 \\
54 \\
59 \\
60 \\
63 \\
60 \\
50 \\
57\end{array}$ & $\begin{array}{r}(2) \\
(6) \\
(3) \\
(5) \\
(1) \\
(4) \\
(8) \\
(9) \\
(7) \\
(16) \\
(14) \\
(11) \\
(9) \\
(11) \\
(17) \\
(15)\end{array}$ \\
\hline
\end{tabular}

pretended to have done so as students. In order of rank the 6 most highly valued items in 1969 remained most popular, and the least popular were still unpopular in 1976.

Of the specific questions about paediatric teaching which were answered in both surveys, there was little difference between the student's opinion and his opinion 7 years later. Thus in $1969,73 \%$ considered that 'teaching on how to examine children' was adequate, compared with $80 \%$ in 1976 . There was only one question for which there was an appreciable change of opinion. In $1969,60 \%$ of the students considered 'teaching on how to communicate with parents' to be adequate, but in 1976 fewer than half, $44 \%$, thought it had been adequate. There was no significant association between changes of opinion and the person's career or aspirations.

\section{Discussion}

The survey has shown that the opinion of clinical students at the end of their paediatric appointment was a reliable guide to their evaluation of the teaching 6 or 8 years later in the light of varied postgraduate training, present careers, and aspirations. Grading the components of the course in rank order for 'value to medical education' showed that the 6 most popular items in 1969 were still considered the best in retrospect, and the least popular were still unpopular. The other changes were merely minor. (The paediatric teachers of 1969 will, no doubt, be relieved to find that the radiologist's $x$-ray tutorials which were 'top of the pops' in 1969, although still extremely popular in retrospect, had been deposed by a wholly paediatric item. Perhaps experience and maturity make a man more appreciative of substance than shadows.)

The qualitative answers to a number of questions about the teachers and teaching showed no significant difference between the opinion at the time and that 7 years later, except for one item. As students, $60 \%$ had considered the teaching of "communicating with parents' to be adequate. In retrospect only $44 \%$ thought it was so. This is surprising because the paediatric course at that time devoted an unusually large amount of time to communication problems and included teachers who were particularly interested in these problems and in discussing them with students.

Student assessment of education was formally introduced in 1924 in the University of Washington. It was slow to gain acceptance in Britain, and particularly slow to be introduced into medical education. Like so many good innovations it was introduced to British medical teaching and paediatrics by Drs P. R. Evans and R. C. Mac Keith. In 
1948 they inaugurated formal student evaluation of teachers and teaching in the Department of Paediatrics at Guy's Hospital, London, where it has been a regular feature ever since. A previous study (Meadow, 1970) showed that it was appreciated by the students, and accepted with reasonable grace by the staff, most of whom found it helpful. It was clear from that study that the enthusiasm and skill of the teacher was much more important to the students than the method, the situation, or the subject. The popularity of the tutorials waxed and waned according to the name of the tutor. Since the assessment of clinical teaching is the same 7 years later, it seems that the personality and skills of the teacher must still be the most important aspect of any component of the course. It is because of the importance of the individual teacher that it would be false to attach too much relevance to the value of the different items of the paediatric course in the Table. It is not 'radiology tutorials' that are popular, but 'Dr Dow, the radiologist, teaching'.

Student assessment of clinical teaching serves many functions. The students enjoy it, and it has a certain psychotherapeutic value. Their comments are usually considerate and constructive and, occasionally, very witty. Administrative faults in the course come to light and the course can be gradually modified in the light of consistent comments by successive groups. Teachers view this sort of assessment with mixed feelings; some prefer to judge than be judged. If the completed questionnaires are circulated to all teachers, they make compulsive reading-where else can one read the comments that one longs to say to colleagues, but dare not? They are an effective way of modifying bad teaching habits. If enough write ' $\mathrm{Dr} X$ is always late' it is likely that $\operatorname{Dr} X$ will become more punctual. Fortunately most students are charitable and find things to praise as well as criticise and with praise the teachers are likely to teach with increased effort and respect.

There have been many studies about the ways in which student evaluation of teaching can be made more effective, and there are useful guidelines available for those constructing questionnaires (Page, 1974). However, many of those who have encouraged student evaluation of teaching and teachers have doubted the long-term validity of that assessment. How can a student expect to assess the value of teaching which is aimed at helping him several years later in work of which he has had no experience? This study shows that 5 or 6 years after qualifying, doctors still regard as most valuable those aspects of the course which they valued most as clinical students. Student assessment of clinical teaching has more relevance than many of us thought.

I am grateful to Mrs Aileen Williams for her efficient administrative help.

\section{Appendix}

Paediatric appointment

During the three months, how useful to your medical education did you find each of the following? Please tick the appropriate column (note that there is a 'Not experienced' column if you had little or none of a particular item, or do not remember it!)

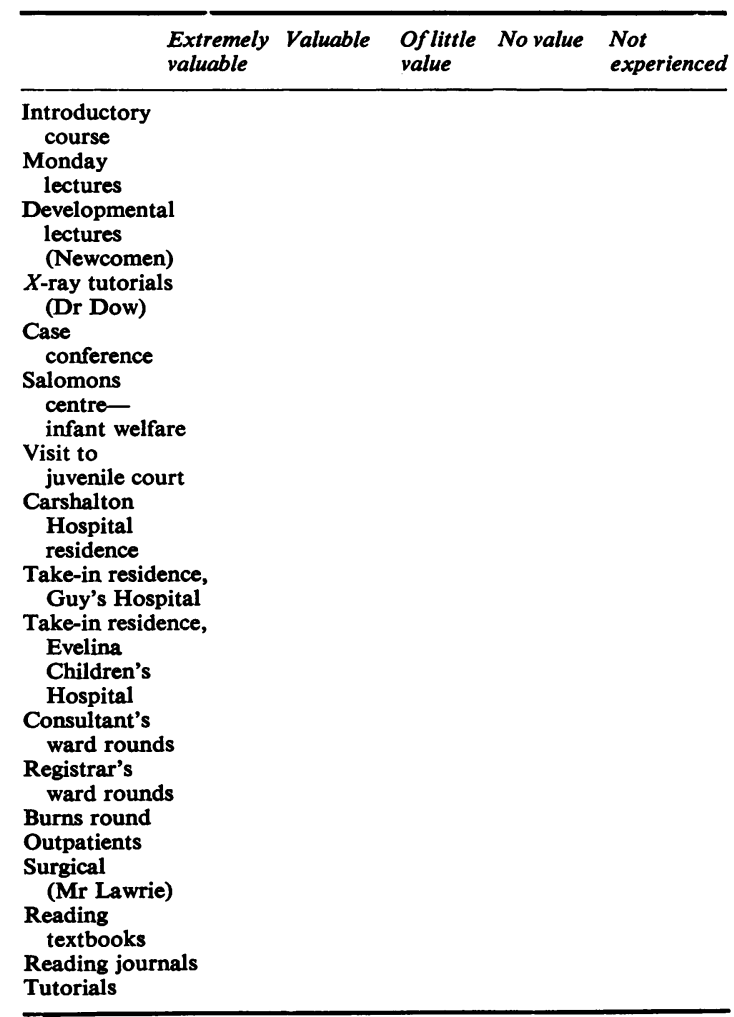

\section{References}

Meadow, R. (1970). Student assessment of clinical teaching. Guy's Hospital Reports, 119, 263-274.

Page, C. F. (1974). Student Evaluation of Teaching. The American Experience. Society for Research into Higher Education: London.

Correspondence to Dr S. R. Meadow, Medical Education Centre, Seacroft Hospital, York Road, Leeds LS14 6UH. 